\title{
First report of recombination in Potato yellow vein virus (PYVV) in Colombia
}

\author{
Giovanni Chaves-Bedoya ${ }^{1}$, Karen Cubillos² \& Mónica Guzmán-Barney² \\ 'PLANTAE Research Group, Faculdad de Ciencias Basicas, Universidad Francisco de Paula Santander, Avenida Gran \\ Colombia No. 12e96, Barrio Colsag, Cúcuta, Colombia; ${ }^{2}$ Laboratorio de Biología Molecular de Vírus, IBUN, Universidad \\ Nacional de Colombia, Carrera 45 No 26-85, Bogotá, Colombia
}

Author for correspondence: Giovanni Chaves-Bedoya, e-mail: gchavesb@ufps.edu.co

\begin{abstract}
Potato yellow vein virus (PYVV) is currently one of the most important viruses that infects potatoes in Colombia and other Andean countries, causing losses in the production of tubers ranging from $25 \%$ to $50 \%$. This study analyzed the genetic variability of different viral isolates collected in the department of Nariño, Colombia, through bioinformatics analysis of the sequences of three genes encoding the capsid protein (CP), the heat-shock protein 70 (Hsp70) and the minor capsid protein (CPm). We found that CPm is the gene that shows greater diversity, with higher values of nucleotide substitution and evidence of recombination. Based on an analysis of the haplotype map using nucleotide sequences of the CPm, we propose a model of putative recombination in this genomic region. The non-recombinant segments are supported by the results of the program GARD (Genetic Algorithm for Recombination Detection), phylogenetic trees and the paired values of genetic distances of each non-recombinant segments. The model clearly shows that the amino region of the CPm is prone to recombination. To our knowledge, this is the first report of genetic recombination as an evolutionary strategy in the CPm of PYVV.
\end{abstract}

Key words: Crinivirus, Solanum tuberosum, genetic variability, minor coat protein.

\section{INTRODUCTION}

Members of the genus Crinivirus (family Closteroviridae) are emerging plant viruses in many parts of the world. An important factor contributing to the increase in the incidence of these viruses is their association with, and transmission by whitefly vectors that have increased in distribution in the last several decades (Stewart et al., 2010). Potato yellow vein virus (PYVV) is a member of the Crinivirus genus (Martelli et al., 2012) transmitted by the whitefly Trialeurodes vaporariorum (Westwood), responsible for a yellowing disease in potato plants. PYVV was observed for the first time in the Department of Antioquia, Colombia, in the early 1940's (Salazar et al., 2000).

Variability among members of the family Closteroviridae was investigated at the molecular level in different genomes (Rubio et al., 2001; Marco \& Aranda, 2005; Rodríguez et al., 2010). For PYVV, genetic variability studies have been limited to the gene encoding the major capsid protein (CP) using approaches such as single-strand conformation polymorphism (SSCP) analysis (Offei et al., 2004), restriction fragment length polymorphism (RFLP) (Guzman et al., 2006), and nucleotide sequence analysis (Rodríguez et al., 2010; Chaves-Bedoya et al., 2013).

Nucleotide composition of plant virus populations provide information about their genetic stability, and the comparison of the nucleotide sequence data from plant viruses isolates from different geographic origins helps in the understanding of their biology. For example, changes in virulence, geographical distribution, and their potential to rise as new epidemics as well as evolutionary mechanisms such recombination. The understanding of this information is key for designing strategies for controlling viruses diseases (Moreno et al., 2004; Tan et al., 2004).

RNA-RNA recombination is one of the strongest forces shaping the genetic diversity of plant RNA viruses (Sztuba-Solinska et al., 2011). Each RNA-based virus seems to be capable of recombining. However, the evolutionary implications of such phenomena for different types of viruses remains to be elucidated (Sztuba-Solinska et al., 2011). Currently there is increasing information on natural recombination in several plant viruses, nevertheless reports about recombination among members of the Closteroviridae family is scarse. Thus far genetic recombination has been detected in the closterovirus Citrus tristeza virus (CTV) (Rubio et al., 2001; Che et al., 2003) and in the criniviruses Strawberry pallidosis associated virus (SPaV) (Tzanetakis \& Martin, 2004), Sweet potato chlorotic stunt virus (SPCSV) (Cuellar et al., 2008) and Blackberry yellow vein associated virus (BYVaV) (Poudel et al., 2012). SPaV is also transmitted by $T$. vaporarium (Tzanetakis et al., 2006).

Since there are no reports about recombination as a possible evolutionary force in the PYVV genome, the aim of this work was to search for and to identify putative break points in the regions encoding the CP, HSP70 and CPm 
genes. For the first time, molecular evidence of multiple genetic recombination in the $\mathrm{CPm}$ coding region of PYVV is reported. The evidence suggests the importance of this genetic region for PYVV evolution.

\section{MATERIAL AND METHODS}

\section{Viral isolates and RNA extraction}

The PYVV isolates were obtained from potato plants exhibiting symptoms of PYVD harvested in the Department of Nariño (South of Colombia). The leaf samples were collected from 30 Solanum tuberosum (group Phureja, or criolla native potato) and $30 \mathrm{~S}$. tuberosum (group Andigena, or yearly potato) plants. The double-stranded viral RNA (dsRNA) was extracted from the leaf samples, previously pulverized in liquid nitrogen, using phenol-chloroform (1:1) and purified with Sephadex G50 columns (Pappu et al., 1993; Cevik et al., 1996; Manjunath et al., 1996; Pappu et al., 2000; Lee et al., 2002; Guzman et al., 2006).

\section{Primer Design}

In this study we used previously described primers (Offei et al., 2004) as well as new, specific CP, CPm, and Hsp70 primers designed based on the alignment of nucleotide sequences reported in GenBank (Livieratos et al., 2004) using the PRIMER3 (Rozen \& Skaletsky, 2000) software. The accession numbers AJ508757 and AJ557129 identifies the sequences used. For the $\mathrm{CP}$ gene, the forward and reverse primers were 5' CTC GAG GAT CCT CAT GGAAAT CCG ATC 3' and 5' CTA CTC AAT AGA TCC TGC TA 3', respectively. For the $\mathrm{CPm}$ gene, the primers were 5' ATG GAT AAG TCT GTT TTA GAT G 3' and 5' TCA AAA GTT TTG ATT CAC ATT C 3'; for the Hsp70 gene, the primers were 5' TGC CCT CTA TCT TCA ATA CCA G 3' and 5' CAC TTC AAA AAT TAT CCT ACA AAG TGA 3'. To sequence the CPm gene, the internal primer 5' TCT CTC CAG ATC AGG CCA AT 3' was used. The size of the expected fragments was 768 base pairs for the $\mathrm{CP}$ gene, 2024 base pairs for the $\mathrm{CPm}$ gene, and 1664 base pairs for Hsp70 gene.

\section{Amplification of viral RNA}

The RNA was amplified using two-step RT-PCR with $8 \mu \mathrm{RNA}, 20 \mathrm{U} / \mu \mathrm{l}$ Moloney murine leukemia virus
(MMLV) reverse transcripatase (Epicentre), $4 \mathrm{U} / \mu \mathrm{l}$ RNAse (RNAsin; Fermentas), $1 \mathrm{X}$ buffer MMLV, $1 \mathrm{mM}$ dNTPs, and $0.24 \mu \mathrm{M}$ reverse primer in a final volume of $25 \mu \mathrm{l}$. The RT reaction was performed at $42^{\circ} \mathrm{C}$ for $1 \mathrm{~h}$. For the $\mathrm{PCR}$ reaction, $4 \mu \mathrm{l}$ of the RT-PCR reaction, $3.75 \mathrm{U} / \mu \mathrm{l}$ Accuzyme (Bioline), $1.875 \mathrm{U} / \mu \mathrm{l}$ Biolase (Bioline), $1 \mathrm{X}$ Accuzyme buffer, $1 \mathrm{mM}$ $\mathrm{MgCl}_{2}, 0.4 \mathrm{mM} \mathrm{dNTPs}$, and $0.4 \mu \mathrm{M}$ of each primer was used. The final volume of the reaction was adjusted to 25 $\mu 1$. The amplification conditions were as follows: 1 cycle at $94^{\circ} \mathrm{C}$ for $3 \mathrm{~min}, 35$ cycles at $94^{\circ} \mathrm{C}$ for $1 \mathrm{~min}, 55^{\circ} \mathrm{C}$ for $1 \mathrm{~min}$, and the extension time was $68^{\circ} \mathrm{C}$ for $1 \mathrm{~min}$ for the Hsp70 and CP genes and $68^{\circ} \mathrm{C}$ for $1.30 \mathrm{~min}$ for the $\mathrm{CPm}$ gene. A final incubation at $68^{\circ} \mathrm{C}$ for $10 \mathrm{~min}$ was performed. The PCR products were purified using the Wizard SV Gel kit and the PCR Clean-Up System (Promega) and were quantified using the QubitTM dsDNA HS kit (Invitrogen). Accuzyme (Bioline) and Biolase (Bioline) enzymes were used because of their high proof reading capacity.

The 60 field isolates were submitted to RT-PCR and the PCR purified products used for the Single Stranded Chain Polymorphism (SSCP) technique searching for gene variability (data not shown) as already has been shown for other closteroviruses (Rubio et al., 1999; Rubio et al., 2001). Only 34 of the 60 isolates showed variability by SSCP, so these isolates were sent to Macrogen USA for direct nucleotide sequencing of the specific genes: $\mathrm{CP}$ gene, 8 isolates; CPm gene, 12 isolates; and Hsp70 gene, 14 isolates (Table 1).

\section{Sequence analysis}

The PYVV nucleotide sequences were obtained from a single reaction using the direct strand as the reverse. The sequences correspond to the $100 \%$ of the nucleotide sequence of each gene. Sequences of these genes area available in the public database GenBank and are listed in Table 1.

The bioinformatic analysis was performed comparing the 34 nucleotide sequences that were obtained with the only complete genomic sequence of PYVV corresponding to a Peruvian isolate (GenBank accession number AJ557129). So far, there is no strain definition or biological characterization for this virus.

Multiple alignment of nucleotide and deduced amino acids sequences were performed using the ClustalX software

TABLE 1 - Genbank accesion numbers of Colombian PYVV isolates analyzed. In bold, PYVV isolates from S. tuberosum group Phureja.

\begin{tabular}{cccc}
\hline \hline & GP & Gene & Hsp70 \\
\hline \multirow{3}{*}{ Isolates } & CPm & JN701958, JN701959 \\
& JN701950, JN701951 & JN701972, JN701973 & JN701960, JN701961 \\
& JN701952, JN701953 & JN701974, JN701975 & JN701962, JN701963 \\
& JN701954, JN701955 & JN701976, JN701977 & JN701964, JN701965 \\
& JN701956, JN701957 & JN701978, JN701979 & JN701966, JN701967 JN701969 \\
& & JN701980, JN701981 & JN701970, JN701971 \\
\hline
\end{tabular}


(Thompson et al., 1997) with the default values of multiple alignment parameters, or the Martinez/Needleman-Wunsch algorithms from the MegAlign (version 5.0) program of the DNASTAR software. The Martinez/Needleman-Wunsch algorithms were also used to calculate a pairwise distance matrix between nucleotide sequences. The phylogenetic relationships of the nucleotide sequences of each gene were inferred using the maximum likelihood method. The evolutionary distances were calculated using the Kimura 2-parameter method (Kimura, 1980) using 1000 replications to estimate the confidence of the taxon grouping in tree branches (Felsenstein, 1985). The analyses were performed using the MEGA 5 software (Tamura et al., 2011).

\section{Recombination analysis and recombination model based on a haplotype map}

The search for evidence of recombination was performed using the GARD algorithm (Kosakovsky et al., 2006) in the remote server Datamonkey (Delport et al., 2010). GARD scans alignments for evidence of phylogenetic incongruence. The nucleotide substitution model was selected automatically before being applied to the recombination-site analysis. This must be done because the use of an inadequate model of nucleotide substitution may lead to differences in the results (Kosakovsky \& Frost, 2005). The putative breakpoints suggested by GARD were further visually located in a haplotype map generated, removing indels and excluding infinite-sites violations using the SNAP program (Price \& Carbone, 2005). Recombination model is proposed on the haplotype map.

In the model, viral isolates were grouped with the support of the results of the recombination analysis (GARD), the phylogenetic trees and pair distances between all the isolates in segments 1-80, 79-114, 114-135, 136-317, 319-382, 379-491, 490-546, 541-735, 736-937, 937-1551, 1552-1636 and 1636-2025 (Figure 1).

In the grouping a pattern of gray scale was used in order to facilitate the recognition of the non-recombinant segments and putative break points. For example, in the $\mathrm{CPm}$ gene analysis, in the first 80 nucleotides of the $\mathrm{CPm}$ the nucleotide similarity between isolates is $100 \%$ (with the exception of the isolate JN701979). This segment, in all isolates, was highlighted in dark gray (70\%). Subsequently, any segment in which the isolates were sharing nucleotide similarities higher than $93 \%$ was highlighted with the same dark gray color. The criterion for selecting nucleotide similarity of $93 \%$ for grouping PYVV isolates was the frequency distribution of the percentages of similarity on the basis of 436 nucleotide sequence comparisons (Figure 1). The segments in which the isolates shared nucleotide similarities below $93 \%$ were highlighted with a different color.

If two isolates in a given nucleotide region share a different gray scale color it indicates that among them the similarity is close or equal to $100 \%$, but less than $93 \%$ with the others, suggesting a possible different ancestor. For instance, in the segment 135-317 (Figure 3) the isolates
JN701977 and JN701979 have a similarity of 100\%, but with the other isolates the similarity is below $93 \%(62.1 \%$ $90.7 \%)$. Therefore this was highlighted in gray to $40 \%$. The isolates JN701974 and JN701978 have 100\% similarity, but a similarity below $93 \%$ with the other isolates so this was highlighted in gray to $20 \%$. The isolate JN701975 has a nucleotide similarity below $93 \%$ with all the other isolates and as such it is highlighted in gray to $10 \%$. Finally, in this segment the other isolates share similarities above $93 \%$ and were highlighted in dark gray $(70 \%)$. The proposed model of recombination in the CPm of PYVV was drawn using the Canvas program for Mac, version 9.0.

\section{RESULTS}

\section{Sequence analyses}

Nucleotide sequence analyses revealed differences in the genetic variability among the three PYVV genes. The mean evolutionary diversity for the entire population in the $\mathrm{CPm}$ is 0.064 ( $\mathrm{sd}=0.003)$; $\mathrm{CP}$ and $\mathrm{Hsp} 70$ coding regions have a nucleotide diversity of $0.010(\mathrm{sd}=0.003)$. Data analysis shows that genes of PYVV isolates obtained from S. tuberosum group Andigena (AG) has a higher number of substitutions per site compared with those from $S$. tuberosum group Phureja (PhG) except in the $\mathrm{CPm}$ coding region where the nucleotide substitution is 0.046 for $A G$ and 0.084 for $\mathrm{PhG}$. The nucleotide diversity values for gene and host are indicated in Table 2.

\section{Phylogenetic trees and GARD analysis}

Phylogenetic trees were built from the alignment of nucleotides and graphed on the same scale to facilitate comparisons. The $\mathrm{CPm}$ coding region has the largest nucleotide substitutions per site, i.e., it is the more variable, followed by the Hsp70 and finally the CP. The phylogenetic trees did not allow for the determining of the correlation between viral isolates and the host from which they were obtained, e.g. AG or PhG (Figure 2).

On the other hand GARD analysis found no evidence of recombination in the $\mathrm{CP}$, however, the analysis suggests the presence of a breakpoint in the position 778 of the region coding for Hsp70 (data not shown) and at least ten breakpoints in the region coding for the CPm located at positions $80,135,317,476,541,735,927,1551,1636$ and 1819 according to Kishino-Hasegawa (KH) test (Kishino \& Hasegawa, 1989). Breakpoints in positions 541 and 1819 are highly significant.

\section{Recombination model}

Based on information from paired values of genetic distances, phylogenetic trees, recombinant segments defined by GARD and haplotype map analysis, a model of the possible evolutionary relationships is proposed among isolates of PYVV (Figure 3). The haplotype map was used to visually identify non-recombinant segments and breakpoints detected by GARD. Haplotype map 


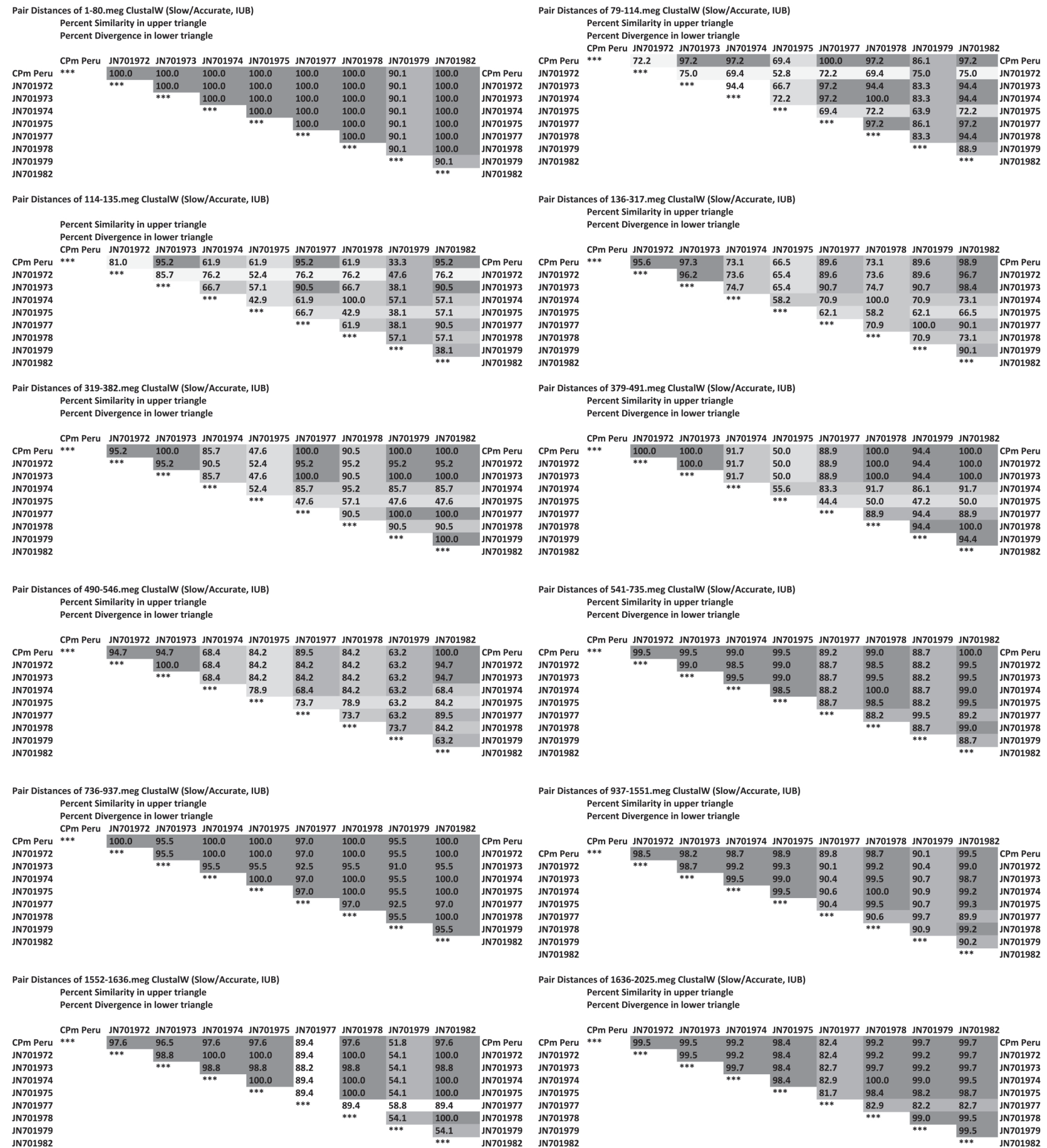

FIGURE 1 - Pairwise distances between different genomic regions of the CPm gene of Potato yellow vein virus (PYVV). Grayscale patterns correspond to the segment in the haplotype map depicted in Figure 3.

analysis of $\mathrm{CPm}$ reveals clear signals of recombination mainly in the $\mathrm{N}$-terminal and central region. The proposed model of recombination suggests CPm of PYVV is highly recombinant mainly in the first $1 / 3$ of the sequence around positions 80 and 541 .

\section{DISCUSION}

The genetic variability of PYVV based in three different genes suggests that in Colombia there are few variants of this virus, with high nucleotide conservation in 
TABLE 2 - Nucleotide diversity values for different PYVV genes in each host.

\begin{tabular}{llc}
\hline \hline Gene & Host $^{\text {a }}$ & Nucleotide diversity \\
\hline $\mathrm{CP}$ & $\mathrm{AG}$ & 0.010 \\
& $\mathrm{PhG}$ & 0.008 \\
$\mathrm{Hsp} 70$ & $\mathrm{AG}$ & 0.016 \\
& $\mathrm{PhG}$ & 0.005 \\
$\mathrm{CPm}$ & $\mathrm{AG}$ & 0.046 \\
& $\mathrm{PhG}$ & 0.084 \\
\hline
\end{tabular}

a AG, Solanum tuberosum grop Andigena; PhG, S. tuberosum group Phureja

the $\mathrm{CP}$ and Hsp70 coding regions indicating a high genetic constrain. On the other hand, the substitution of bases and amino acids in the $\mathrm{CPm}$ indicates minor restrictions suggesting the importance of this region in the evolutionary processes of PYVV including genetic recombination.

PYVV presents a high genetic similarity in the studied genes; nevertheless, some isolates have nucleotide similarities below $75 \%$ in some regions. According to the criterion of species demarcation among criniviruses (King et al., 2012), these genetic segments could come from a different virus. The generation of new sequences will allow in the discarding or confirmation of interspecific recombination in PYVV.

It is well known that recombination is a very important process for the evolution of plant viruses (Roossinck, 2003) and it is common both intraspecific and interspecific. Recombination is particularly significant in persistent infections in which multiple viral genotypes are simultaneously replicated in a host generating genetic variants, some of which have new characteristics of pathogenicity and some others can colonize new hosts.

Our model of recombination in PYVV proposes that isolates JN701977 (AG host) and JN701979 (PhG host) have a different genetic background in most of the CPm. The isolates JN701975, JN701974 and JN701978 are formed by the contribution of two recombinant ancestors as the isolate JN701972. No evidence of recombination was found in isolates JN701982, JN701973 and the Peruvian accession. In spite of the GARD results, no recombination was visualized in position 927 on the haplotype map. The lack of evidence of recombination in isolates JN701982, JN701973 and the Peruvian strain does not mean that they are not recombinant. This may be possible due to the high genetic similarity among the isolates, or because the possible ancestral recombination event is hidden by subsequent mutations (Posada et al., 2002).

Nucleotide variability and clear and abundant points of recombination detected in the $\mathrm{CPm}$ of remaining PYVV isolates suggest that this region is a putative hot spot of recombination and an indicator of a possible recent molecular event (Tomimura et al., 2003), or a recent emergence (Tan et al., 2004). The evidence also suggests that this gene may play a key role in the diversity and evolution of PYVV with a possible role in the adaptation or host specificity. However, there is no evidence for these functions in this gene for PYVV. Nevertheless, recently the CPm of the crinivirus Lettuce infectious yellows virus (LIYV) was reported as required for whitefly transmission (Stewart et al., 2010). Although the biological significance of the recombination of the CPm gene in PYVV is not yet understood, it is important to note that within the Closteroviridae family, the $\mathrm{CPm}$ has been reported as a protein involved in cell-to-cell transportation and assembly (Alzhanova et al., 2001). So the evidence obtained in this study of $\mathrm{CPm}$ gene recombination in some PYVV isolates suggest that this re-emergent virus could be trying to improve its performance for transmission. Furthermore, CPm of PYVV could be indispensable in transmission by its vector $T$. vaporariorum, nonetheless more work is needed to test this hypothesis.

Recombination in PYVV occurs in viral isolates from both AG and PhG hosts (Table 1). However, among the sequences analyzed recombination is likely more frequent in PYVV isolates infecting PhG hosts.

In contrast to the $\mathrm{CPm}$, the genetic variability of the Hsp70 and CP of PYVV is low, as has been previously reported (Offei et al., 2004; Guzman et al., 2006; Rodríguez et al., 2010) and coinciding with a recent study based on 69 nucleotide sequences of the CP reported in different years and locations in Colombia (Chaves-Bedoya et al., 2013).

High genetic stability found in the CP and Hsp70 of PYVV isolates from two different hosts could be attributed to negative or purifying selection that allowed it to maintain the functional integrity of the viral genome as proposed for Cucurbit yellow stunting disorder virus (Marco \& Aranda, 2005). Studies of other members of the Closteroviridae family suggest that the genes in the genomic arrangement specific for this family are likely conserved because of the biological implications of the proteins produced (Rubio et al., 1999). It is known that capsid proteins in viruses transmitted by vectors are subject to purifying selection due to the interactions between capsid proteins and cellular receptors in the vector, which are necessary for successful transmission (Chare \& Holmes, 2004). Therefore, it is common to find that even though these genes have the potential to mutate, as is suggested by the number of nonsynonymous substitutions, they preserve the more stable genomes because of negative selection on the new variants, causing the prevalence of one viral variant in the isolates.

The results obtained in this study are new and important when taking into account the variability of the three genes of PYVV in two potato species analyzed (S. tuberosum andigena and S. phureja) collected at the Colombian Department of Nariño, which is one of the most important growers of potatoes, and center of genetic diversity. Although we cannot yet correlate the genes variability with each one of the hosts, or the significance of changes within an isolate, the results suggest that mutation and recombination are very important process for $\mathrm{CPm}$ evolution. Despite these mechanisms, the genetic polymorphism of PYVV is very 

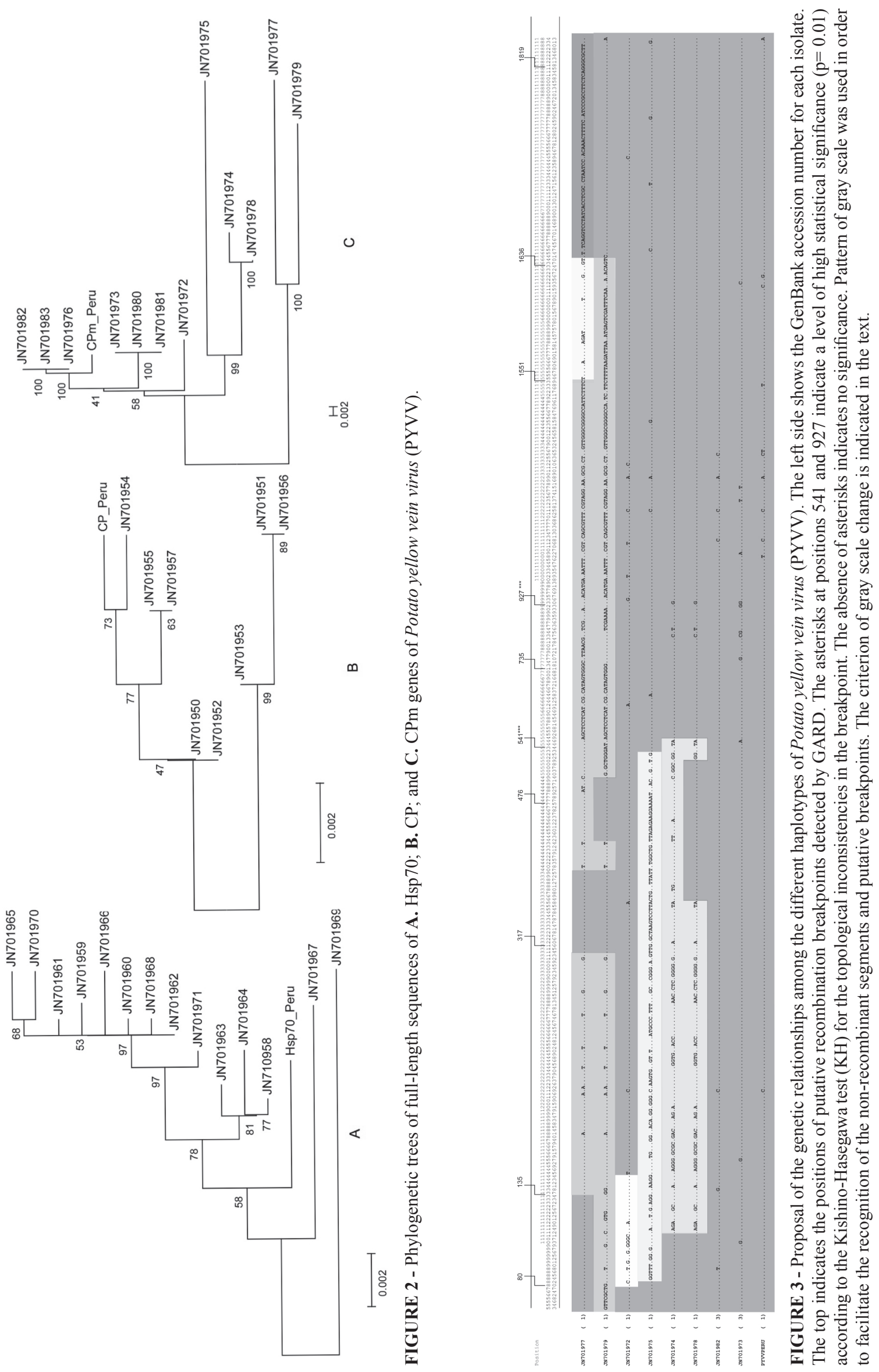
low considering it is a RNA virus. More studies are needed to estimate the prevalence of the recombinant isolates and for their biological characterization.

\section{ACKNOWLEDGEMENTS}

We are grateful to Colciencias, project 115-2007, project MARD MARD2007S4654-69, Dr. Liliana Franco (Universidad Militar Nueva Granada), and Patricia Rodríguez (Laboratorio de Vírus de Plantas, IBUN). We are also grateful to the Language Center from Universidad Francisco de Paula Santander in Cúcuta-Colombia for grammar corrections of the manuscript.

\section{REFERENCES}

Alzhanova DV, Napuli AJ, Creamer R, Dolja VV (2001) Cell-tocell movement and assembly of a plant closterovirus: Roles for the capsid proteins and Hsp70 homolog. EMBO Journal 20:69977007.

Cevik B, Pappu SS, Pappu HR, Benscher D, Irey M, Lee RF, Niblett CL (1996) Application of bi-directional PCR to Citrus tristeza virus: Detection and strain differentiation. In: 13th Meeting of the IOCV, Proceedings... Riverside, CA, USA. International Organization of Citrus Virologists. pp. 17-24.

Chare ER, Holmes EC (2004) Selection pressures in the capsid genes of plant RNA viruses reflect mode of transmission. Journal of General Virology 85:3149-3157.

Chaves-Bedoya G, Guzman-Barney M, Ortiz-Rojas LY (2013) Genetic structure and evidence of putative Darwinian diversifying selection in the Potato yellow vein virus (PYVV). Agronomia Colombiana 31:161-168.

Che X, Dawson WO, Bar-Joseph M (2003) Defective RNAs of Citrus tristeza virus analogous to Crinivirus genomic RNAs. Virology 310:298-309.

Cuellar WJ, Tairo F, Kreuze JF, Valkonen JP (2008) Analysis of gene content in Sweet potato chlorotic stunt virus RNA1 reveals the presence of the p22 RNA silencing suppressor in only a few isolates: Implications for viral evolution and synergism. Journal of General Virology 89:573-582.

Delport W, Poon AF, Frost SD, Kosakovsky PSL (2010) Datamonkey 2010: A suite of phylogenetic analysis tools for evolutionary biology. Bioinformatics 26:2455-2457.

Felsenstein J (1985) Confidence limits on phylogenies: An approach using the bootstrap. Evolution 39:783-791.

Guzman M, Ruiz E, Arciniegas N, Coutts RH (2006) Occurrence and variability of Potato yellow vein virus in three departments of Colombia. Journal of Phytopathology 154:748-750.

Kimura M (1980) A simple method for estimating evolutionary rates of base substitutions through comparative studies of nucleotide sequences. Journal of Molecular Evolution 16:111-20.

King AMQ, Lefkowitz E, Adams MJ, Carstens EB (Eds.) (2012) Viral Taxonomy. Ninth Report of the International Committee on Taxonomy of Viruses. London, UK. Elsevier Academic Press.

Kishino H, Hasegawa M (1989) Evaluation of the maximum likelihood estimate of the evolutionary tree topologies from DNA sequence data, and the branching order in hominoidea. Journal of Molecular Evolution 29:170-179.

Kosakovsky PSL, Frost SD (2005) Not so different after all: A comparison of methods for detecting amino acid sites under selection. Molecular Biology and Evolution 22:1208-1222.

Kosakovsky PSL, Posada D, Gravenor MB, Woelk CH, Frost SD (2006) Automated phylogenetic detection of recombination using a genetic algorithm. Molecular Biology and Evolution 23:18911901.

Lee RF, McConnell P, Manjunath KL, Cevik B, Nikolaeva OV, Dekkers MGH, Niblett CL (2002) The Citrus tristeza virus epidemic. In: 15th Meeting of the IOCV, Proceedings... Riverside, CA, USA. International Organization of Citrus Virologists. pp. 95101.

Livieratos IC, Eliasco E, Muller G, Olsthoorn RC, Salazar LF, Pleij CW, Coutts RH (2004) Analysis of the RNA of Potato yellow vein virus: Evidence for a tripartite genome and conserved 3'-terminal structures among members of the genus Crinivirus. Journal of General Virology 85:2065-2075.

Manjunath KL, Pappu HR, Lee CL, Niblett CL, Civerolo EL (1996) Studies on the coat protein genes of four isolates of Citrus tristeza Closterovirus from India: cloning, sequencing and expression. In: 13th Meeting of the IOCV, Proceedings... Riverside, CA, USA. International Organization of Citrus Virologists. pp. 20-27.

Marco CF, Aranda MA (2005) Genetic diversity of a natural population of Cucurbit yellow stunting disorder virus. Journal of General Virology 86:815-822.

Martelli GP, Ghanem-Sabanadzovic NA, Agranovsky AA, Rwahnih MA, Dolja VV, Dovas CI, Fuchs M, Gugerli JS, Hu JS, Jelkmann W, Katis NI, Maliogka VI, Melzer MJ, Menzel W, Minafra A, Rott ME, Rowhani A, Sabanadzovic S, Saldarelli P (2012) Taxonomic revision of the family Closteroviridae with special reference to the gravepine leafroll-associated members of the genus Ampelovirus and the putative species unassigned to the family. Journal of Plant Pathology 94:7-19.

Moreno IM, Malpica JM, Diaz-Pendon JA, Moriones E, Fraile A, Garcia-Arenal F (2004) Variability and genetic structure of the population of Watermelon mosaic virus infecting melon in Spain. Virology 318:451-460.

Offei SK, Arciniegas N, Muller G, Guzman M, Salazar LF, Coutts RH (2004) Molecular variation of Potato yellow vein virus isolates. Archives of Virology 149:821-827.

Pappu H, Pappu S, Niblett C, Lee R, Civerolo E (1993) Comparative sequence analysis of the coat proteins of biologically distinct Citrus tristeza Closterovirus isolates. Virus Genes 7:255-264.

Pappu SS, Bhat AI, Pappu HR, Deom CM, Culbreath AK (2000) Phylogenetic studies of tospoviruses (family Bunyaviridae) based on intergenic region sequences of small and medium genomic RNAs. Archives of Virology 145:1035-1045.

Posada D, Crandall KA, Holmes EC (2002) Recombination in evolutionary genomics. Annual Reviews of Genetics 36:75-97.

Poudel B, Sabanadzovic S, Bujarski J, Tzanetakis IE (2012) Population structure of Blackberry yellow vein associated virus, an emerging Crinivirus. Virus Research 169:272-275.

Price EW, Carbone I (2005) SNAP: Workbench management tool for evolutionary population genetic analysis. Bioinformatics 


\section{1:402-404.}

Rodríguez P, Chaves-Bedoya G, Franco-Lara L, Guzmán M (2010) Low molecular variability of Potato yellow vein virus (PYVV) isolates of Solanum phureja and Solanum tuberosum from Colombia. Phytopathology 100:S176.

Roossinck MJ (2003) Plant RNA virus evolution. Current Opinion in Microbiology 6:406-409.

Rozen S, Skaletsky H (2000) Primer3 on the WWW for general users and for biologist programmers. Methods in Molecular Biology 132:365-386.

Rubio L, Ayllon MA, Kong P, Fernandez A, Polek M, Guerri J, Moreno P, Falk BW (2001) Genetic variation of Citrus tristeza virus isolates from California and Spain: Evidence for mixed infections and recombination. Journal of Virology 75:8054-8062.

Rubio L, Soong J, Kao J, Falk BW (1999) Geographic distribution and molecular variation of isolates of three whitefly-borne closteroviruses of cucurbits: Lettuce infectious yellows virus, Cucurbit yellow stunting disorder virus, and Beet pseudo-yellows virus. Phytopathology 89:707-711.

Salazar LF, Miller G, Querci M, Zapata JL, Owens RA (2000) Potato yellow vein virus: Its host range, distribution in South America and identification as a Crinivirus transmitted by Trialeurodes vaporariorum. Annals of Applied Biology 137:7-19.

Stewart LR, Medina V, Tian T, Turina M, Falk BW, Ng JC (2010) A mutation in the Lettuce infectious yellows virus minor coat protein disrupts whitefly transmission but not in planta systemic movement. Journal of Virology 84:12165-12173.
Sztuba-Solinska J, Urbanowicz A, Figlerowicz M, Bujarski JJ (2011) RNA-RNA recombination in plant virus replication and evolution. Annual Review of Phytopathology 49:415-443.

Tamura K, Peterson D, Peterson N, Stecher G, Nei M, Kumar S (2011) MEGA5: Molecular evolutionary genetics analysis using maximum likelihood, evolutionary distance, and maximum parsimony methods. Molecular Biology and Evolution 28:27312739.

Tan Z, Wada Y, Chen J, Ohshima K (2004) Inter- and intralineage recombinants are common in natural populations of Turnip mosaic virus. Journal of General Virology 85:2683-2696.

Thompson JD, Gibson TJ, Plewniak F, Jeanmougin F, Higgins DG (1997) The CLUSTAL_X windows interface: Flexible strategies for multiple sequence alignment aided by quality analysis tools. Nucleic Acids Research 25:4876-4882.

Tomimura K, Gibbs AJ, Jenner CE, Walsh JA, Ohshima K (2003) The phylogeny of Turnip mosaic virus: Comparisons of 38 genomic sequences reveal a Eurasian origin and a recent 'emergence' in east Asia. Molecular Ecology 12:2099-2111.

Tzanetakis IE, Martin RR (2004) Complete nucleotide sequence of a strawberry isolate of Beet pseudoyellows virus. Virus Genes 28:239-246.

Tzanetakis IE, Wintermantel WM, Cortez AA, Barnes JE, Barret SM, Bolda MP, Martin RR (2006) Epidemiology of Strawberry pallidosis-associated virus and occurrence of pallidosis disease in North America. Plant Disease 90:1343-1346.

TPP-2013-0143

Submitted: 16 August 2013

Revisions requested: 6 September 2013

Accepted: 13 December 2013

Section Editor: Jorge Alberto Marques Rezende 